\title{
Clinical Manifestations of Liver and Renal Impairments in Asymptomatic, Moderate and Severe COVID-19 Patients of Madinah City of Saudi Arabia: A Retrospective Analysis
}

Firdous beigh ( $\nabla$ fbeigh@taibahu.edu.sa )

Taibah University

Nidda Syeed

Taibah University

Walaa Saeed

Taibah University

Ziab Alahmadey

Kingdom of Saudi Arabia

Ibrahim Seedi

Kingdom of Saudi Arabia

Research article

Keywords: COVID-19, Liver and Kidney function, Madinah, Saudi Arabia

Posted Date: September 8th, 2020

DOI: https://doi.org/10.21203/rs.3.rs-62268/v1

License: (1) This work is licensed under a Creative Commons Attribution 4.0 International License. Read

Full License 


\section{Abstract}

Background: Coronavirus disease (COVID-19) is a budding infectious disease that has affected various countries globally.The aim of this study was to analyze the effect of COVID-19 disease on liver and kidney functions and to determine their association with the severity and mortality of disease.

Methods: A total of 100 confirmed COVID-19 adult patients from Madinah city of Saudi Arabia hospitalized between April 28, and June 30, 2020 were included,and categorized into asymptomatic,mild to moderate and severely ill patients.We analyzed the clinical status of liver and renal functioning in all of the three groups.

Results: The majority of patients (51\%) were diagnosed with mild to moderate disease, $27 \%$ of patients were severely ill and $22 \%$ of patients were asymptomatic. The liver and renal functional analysis showed that the severity of the COVID-19 patients were significantly associated with the kidney and renal impairments exhibiting higher levels of ALT, AST, Creatinine, Urea levels $(P<0.05)$. Furthermore, in this study, a novel association is found between high $\mathrm{Na}$ and $\mathrm{Cl}$ levels with the severely ill COVID-19 patients.

Conclusion: We concluded from the present study that a significant percentage of COVID-19 patients continued to have a normal liver and renal function during the course of their disease. Nevertheless, severely ill COVID-19 patients were more prone to have abnormal liver and renal functions. During the course of treatment, the patients had a gradual normalization of their liver and kidney parameters and subsequently achieved a complete normal liver and renal functions upon discharge with no mortality.

\section{Introduction}

The recent SARS-COV2 coronavirus that started in the Wuhan city of China, is the crucial international health catastrophe of the present time and one of the greatest healthcare challenge the world is facing currently. More than 10.3 million coronavirus cases have been reported globally. Coronavirus disease-2019 (COVID-19) was declared pandemic by WHO having led to thousands of deaths globally. As of July, more than 216 countries have been affected by the COVID-19 disease with over 13616593 confirmed cases leading to more than 585727 deaths (1). The Ministry of Health have reported 116,021 cases of Novel Coronavirus (COVID$19)$ in the Kingdom of Saudi Arabia.

The clinical indications of the disease usually are fever, cough, fatigue and other signs of respiratory tract infections. In severely ill patients, individuals show symptoms of pneumonia with atypical CT chest, related with complications of severe acute respiratory distress syndrome, acute cardiac injury, and renal failure leading eventually to death. Recent researches have revealed that more than half of COVID-19 patients showed erratic levels of liver and renal disorder (2). Several COVID-19 patients with pneumonia have shown renal injury, and the autopsy results of some patients who died from the Covid-19 have shown renal damage sometimes $(3,4)$. However, little is known about the clinical characteristics of kidney related complications. Furthermore, a histopathology study of liver biopsy samples from a patient who died from COVID-19 revealed moderate microvesicular steatosis and minor lobular and portal activity, signifying that SARS-CoV-2 could be the underlying cause of this liver damage(5) Nevertheless, recent researches have shed light on the impact of COVID-19 on various body organs, but still, there is a paucity of data related to the clinical outcomes of this 
disease. Hence, the aim of the present study was to analyze the clinical significance of liver and renal parameters in COVID-19 patients admitted to the referral hospital in the Madinah region of Saudi Arabia.

In the present study, we sought to analyze the clinical significance of liver and renal function changes and evaluate its relationship with the disease progression in COVID-19 patients.

\section{Methods}

\section{Patients and Data Collection}

This retrospective study was conducted in the Ohud Hospital and King Fahd Hospital of Madinah region, Saudi Arabia. In the present case-control study, a total of 100 cases of Covid-19 patients and 90 healthy individuals as the control group were randomly selected. The patient records included the clinical and laboratory data that was used for analysis. All cases were reviewed based on the inclusion and exclusion criteria, the inclusion criteria were patients with confirmed COVID-19 disease. However, those patients were excluded who were having the history of endocrine diseases including hyperthyroidism, hypothyroidism, adrenal disease, and pituitary disease, or history of major renal, liver, heart or neurological disease. Control group was selected based on their recording files that showed no history of major renal, liver, heart, endocrine or neurological disease and matching age with patients. The study was approved by the Ethics Committee of the Faculty of Applied Medical Sciences at Taibah University and Saudi Arabia Ministry of Health, General Administration for Researches \& Studies.

\section{Statistical analysis}

Data was analyzed using the GraphPad Prism Software (version 5.01). Quantitative data which are normally distributed was expressed as percentages, mean, standard deviation and range. T-test was used to compare between the patients and the control group. One-way Anova test (Tukey's multiple comparisons test) was used to compare Severe covid-19 infected patients with Mild and Asymptotic patients.

Also, Multivariate analysis was used based on the Multiple Logistic Regression (severity of covid-19 infection is dependent parameter tested against the biochemical markers). The odds ratio (OR) was calculated with $95 \%$ confidence intervals. All differences were statistically significant at the level of $P \leq 0.05$ or $\leq 0.001$.

\section{Results}

\section{Patient Characteristics}

\section{Baseline and demographic characteristics of Covid-19 patients}

In the present study, 100 patients were diagnosed with Covid- 19 with a mean age of $55.5 \pm 11.6$ years (extremes: 30-80 years). The study subjects include 66 males and 34 Females (Table 1). In our study group, no children or teenagers were infected. The patients with Covid-19 showed increased levels of liver enzymes (ALT, AST), albumin, bilirubin and much elevated levels of Creatinine, urea, $\mathrm{Na}$ and $\mathrm{Cl}$ when compared with the 
control group. Additionally, there was much reduced levels of $\mathrm{K}$ (Table 2). Only those patients were included in the present study who were not having any underlying medical conditions like diabetes, COPD, chronic kidney disease, chronic liver disease, pneumonia.

Furthermore, a comparison between the infected and the control group (Table 3 ) revealed that the concentration of liver enzymes increased significantly in Covid-19 patients when compared to the control group $(P<0.001)$. Also, the levels of bilirubin were higher than the control group $(P<0.001)$. Whereas, the levels of albumin showed a significant decrease in the infected group when compared to the healthy control group $(P=0.02)$. Additionally, there were significant increase in the levels of creatinine, $\mathrm{Na}, \mathrm{Cl}$ and urea in COVID-19 patients compared to the control group $(P<0.001)$. However, a significant decrease in the level $K$ was detected in the COVID-19 patients compared to the control group $(P<0.001)$. A Comparison of the liver biomarker results between the male and female Covid-19 patients using the t-test revealed significance difference in the means between the two gender groups of Covid-19 patients. A statistically significant difference in ALT, AST and bilirubin levels $(P<0.001)$, were found but no significant difference in albumin levels $(P>0.05)$ were seen (Table 4). The Comparison of the renal biomarkers of COVID-19 patients between males and females using T-test analysis showed a significant difference in the levels of Creatinine, uric acid, BUN, $\mathrm{K}$ and $\mathrm{Cl}$ between males and females $(\mathrm{P}<0.05)$ (Table 5).Additionally, we found $7 \%$ of severely ill COVID19 patients had proteinuria. There were significant differences in the levels of ALT, AST, Albumin, Creatinine, $\mathrm{Na}$ and $\mathrm{Cl}$ between severe cases and another two categories $(\mathrm{p}<0.001)$. Additionally, there was a significant difference in the level of bilirubin between the severe and asymptotic cases, but none in mild cases (Table 6).

Moreover, multivariate analysis was done based on the Multiple logistic Regression to measure the effect of Covid-19 infection severity on liver and renal biomarkers. Table 7 indicates that the odds ratios are statistically significant, the confidence intervals $(95 \% \mathrm{Cl})$ suggest that the effects of infection severity on ALT, Bilirubin, could be anywhere from a 0.997 -fold increase to a 6.023 -fold, 1.975- fold increase to 6.010 -fold respectively. A one-unit change in the dependent factor severity of covid-19 infection increases the odds of increasing Creatinine, $\mathrm{Na}$ and $\mathrm{Cl}$ levels by factors of 5.99, 7.039 and 3.009 respectively (Table 7).

\section{Severity Of Covid-19}

According to the national protocol for patients with confirmed COVID-19 infection, all of the patients included in the study were classified into severe, moderate, mild, and asymptomatic based on the results from clinical features, chest radiography, and overall symptoms. Patients with mild symptoms and no abnormal laboratory findings were classified as asymptomatic. Severe cases were defined by, respiratory rate $>30 / \mathrm{min}$, blood oxygen saturation $<93 \%$, PaO2/FiO2 ratio $<300$, Lung infiltrates $>50 \%$ of the lung field within $24-48$ hours. In 
the present study, out of 100 patients, 27 were severely infected, 22 were asymptomatic, 51 were mild to moderately ill. Results of one-way ANOVA tests for differences in the levels of biomarkers between severe cases and mild or asymptomatic cases of Covid-19 were presented in Table 6. A one-way between subjects ANOVA was conducted to compare the levels of liver and renal biomarkers in severe cases with asymptomatic and mile to moderately ill cases.

\section{Mortality}

In the present clinical study, there were no mortalities regardless the high levels of liver and renal biomarkers, which marks the novelty of the study.

\section{Discussion}

In the late December of 2019, the Wuhan City of China experienced an unprecedented outbreak of a cluster of pneumonia cases having mysterious aetiology $(6,7)$. Since then, it has rapidly spread across China and to many other countries across the globe. Recent researches on COVID-19 mainly emphasized on lungs as the main organ affected in the disease, whileas less data is reported regarding the involvement of other organs like liver and kidneys. The involvement of multiple organs including the liver, gastrointestinal tract, and kidney have been previously reported in patients with COVID-19 (8).

Our study is perhaps unique in reporting the impact of severity of covid 19 disease on the liver and renal functioning of the COVID-19 patients with no prior underlying liver or renal impairments. Recent studies have described distinctive levels of elevated liver enzymes in COVID-19 cases, mostly exhibiting higher alanine aminotransferase (ALT) and aspartate aminotransferase (AST) levels accompanied by mildly elevated total bilirubin (TB) levels $(9,10)$. We have found similar kind of results, wherein, the patients with elevated liver enzymes accompanied by moderate to highly elevated direct bilirubin depicted severe illness compared to those who had normal to very mildly elevated results. A similar kind of results were also reported in a study done by Qingxian Cai et al., (11), where high levels of AST was seen in 62\% (8 of 13) of patients who were critically ill and shifted to the intensive care unit (ICU) compared to $25 \%$ (7 of 28 ) of patients who were mildly ill having normal to mildly raised levels of liver enzymes and hence corroborating with our current findings. Furthermore, some of the asymptomatic COVID-19 patients in this study also showed normal or mildly elevated liver enzymes, suggesting that liver damage is more predominant in severe cases compared to mild cases of COVID-19 as also reported in a similar study done by Zhang $C$ et al., (12). However, the reason for the elevation of liver enzymes or liver injury still remains unclear as to whether it is caused by the virus itself or due to a severe inflammatory reaction produced in response to the infection (13). In this connection, a recent study by Hamming et al., has revealed that the novel coronavirus might directly infect the liver cells as the docking receptor of the virus, angiotensin-converting enzyme 2 (ACE2), is released by the cells of both liver and bile-duct, where the virus replicates and consequently invades the cells of the upper respiratory tract and lung tissue and hence the patients develop the clinical symptoms(14). Moreover, a recent pilot study has proposed that an enhanced expression of ACE2 receptor is developed in cholangiocytes (15) signifying that the novel coronavirus may bind directly to the ACE2-positive cholangiocytes and impair the normal liver 
functions. Additionally, cytokine storm and pneumonia-related hypoxia, might add to the liver damage leading to complete or partial liver failure in severely ill COVID-19 patients.

In addition to liver damage, an increased incidence of acute renal injury in COVID-19 patients has also been previously reported. (16). Covid-19 has been shown to impair renal function in several ways, ranging from poor blood flow to the formation of tiny blood clots which can clog the kidneys and prevent urine formation. The current clinical study revealed that the patients suffering with severe cases of COVID-19 are also showing signs of kidney damage, even though they had no history of kidney ailments prior to the infection with the novel coronavirus.

We found the patients who were categorized as severely ill had altered kidney function tests, characterized by elevated serum creatinine, urea and blood urea nitrogen levels as also been reported by Fan $C$ et al. [17]. The altered kidney function can be attributed to the variations in angiotensin-converting enzyme 2 (ACE2) receptor expression leading to kidney dysfunction. ACE2, which is expressed on the brush border apical membrane of the proximal tubules of kidneys, as well as in podocytes at low level (18). Therefore, it is plausible that the virus could enter the podocytes first, infects them, and then binds to ACE2 to enter the kidney tubular cells, that leads to the impaired renal function, as has been reported by Batlle $D$ et al., (19)

Furthermore, we also observed hypernatremia and hyperchloremia in our severely ill COVID - 19 patients, which has not been reported previously. We attribute the elevation of $\mathrm{Na}$ and $\mathrm{Cl}$ to severe water loss due to pyrexia, use of diuretics and high respiration rate. Additionally, there are fair chances of hypernatremia and hyperchloremia in COVID-19 patients due to abnormally low levels of oxygen in the blood, caused by the pneumonia which is common in severe cases of this disease. The large influx of cytokines known as cytokine storm leads to severe inflammation, which can damage the healthy tissues, including that of the kidneys, and therefore we propose an association between the metabolic acidosis (hypernatraemic and hyperchloremia) and the cytokine storm. we further suggest that severity of pneumonia could be an important factor in development of AKI in patients with COVID-19.

The current study has certain limitations, which includes limited number of patients, the patient duration in the hospital was not enough to predict the possibilities of remission of liver and renal damage. We were not able to detect the presence of SARS-CoV-2 in urine samples and hence could not evaluate the correlations between urine virus and kidney complications. Therefore, we recommend repeated and meticulous observation of liver and renal functions in patients with COVID-19 that can help in achieving the optimum mode of treatment and reduce the number of deaths due to organ failure.

\section{Conclusion}

In conclusion, a significant number of patients with COVID-19 maintained their normal liver and kidney functions all through the course of their disease, however, patients who were severely ill had an effect on their liver and Kidney functions, and therefore had elevated ALT, AST, Creatinine, Urea, Sodium, Chlorine and total bilirubin levels. All the COVID-19 patients enrolled in this study did not have any prior liver or kidney abnormalities and hence, this effect could possibly be attributed to the severity of COVID-19 infection. It is pertinent to mention that despite the morbidities associated with liver and renal involvements, these COVID-19 
patients showed a good prognosis and achieved normal liver and Kidney functions upon discharge from the hospital. Although the COVID-19 deaths related to liver and kidney involvement have been reported by several studies. However, there was no mortality associated with the liver and kidney abnormality found in our COVID19 patients possibly because of a less virulent strain of coronavirus or the genetic makeup of the Saudi population. Therefore, further studies on the effect of COVID-19 infection on liver and kidney functions would be helpful in determining the course of treatment to avoid the associated complications and for better clinical management.

\section{Declarations}

Abbreviations - ALT, alanine aminotransferase; AST, aspartate aminotransferase; COVID-19, coronavirus disease 2019;ALB, albumin; TBIL, total bilirubin.Na, Sodium; Cl, Chlorine; COPD, chronic obstructive pulmonary disorder,

- - Ethics approval and consent to participate-The study was approved by the university ethical committee as well as by the ethical committee of Ministry of Health.

- - Consent for publication- All authors have given their consent for publication after reading the journal policies.

- - Availability of data and materials- We declare that all the patient data reported in this study have not been reported in any other study by us or anyone else.

- - Funding- This work was not financially supported by an agency.

- - Competing Interests -All authors declare that they have no competing interests.

- - Authors' contributions-Dr. Walaa compiled the data and did statistics for the study, Dr. Nidda Syeed wrote the manuscript, Dr. Ziab and DR. Ibrahim got the patient data and details for the study and Dr. Firdous Hussain did the overall data compilation and finished the manuscript compiling.

- - Acknowledgements-We highly appreciate all of the hospital team for their efforts in treating the patients and the laboratory staff for data collection of COVID-19, we thank all patients involved in this study.

\section{References}

1. World Health Organization. Novel coronavirus (2019-nCoV) situation reports. https://www.who.int/emergencies/diseases/novel-coronavirus-2019/situation-reports 179.

2. Chau TN, Lee KC, Yao H, Tsang TY, Chow TC, Yeung YC, et al. SARS-asso- ciated viral hepatitis caused by a novel coronavirus: report of three cases. Hepatology. 2004;39:302-10.

3. Wang D, Hu B, Hu C, Zhu F, Liu X, Zhang J, et al. Clinical Characteristics of 138 Hospitalized Patients With 2019 Novel Coronavirus-Infected Pneumonia in Wuhan, China. JAMA. 2020;323(11):1061-9.

4. National Health Commission of the People's Republic of China. Diagnosis and Treatment Protocols of Pneumonia caused by a Novel Coronavirus. March 3, 2020.

https://www.chinadaily.com.cn/pdf/2020/1.Clinical.Protocols.for.the.Diagnosis.and.Treatment.of.COVID19.V7.pdf. 
5. Xu Z, Shi L, Wang Y, Zhang J, Huang L, Zhang C, et al. Pathological findings of COVID-19 associated with acute respiratory distress syndrome. Lancet Respir Med 2020.

6. Li Q, Guan X, Wu P, Wang X, Zhou L, Tong Y, et al. Early transmission dynamics in Wuhan, China, of novel coronavirus-infected pneumonia. N Engl J Med. 2020. https://doi.org/10.1056/NEJMoa2001316.

7. WHO

WHO. Novel Coronavirus-China. 2020. https://www.who.int/csr/don/12-january-2020-novel-coronaviruschina/en/.

8. Chen N, Zhou M, Dong X, et al. Epidemiological and clinical characteristics of 99 cases of 2019 novel coronavirus pneumonia in Wuhan, China: a descriptive study. Lancet. 2020;395:507-13.

9. Guan W-J, Z-Y N, Hu YU, et al. Clinical characteristics of coronavirus disease 2019 in China. N Engl J Med. 2020;382:1708-1720.

10. Ji D, Qin E, Xu J, et al. Implication of nonalcoholic fatty liver diseases (NAFLD) in patients with COVID-19: a preliminary analysis. J Hepatol. 2020.

11. Cai Q, Huang D, Yu H, Zhu Z, Xia Z, Su Y, et al. COVID-19: Abnormal liver function tests. Journal of hepatology. 2020;73(3):566-74.

12. Zhang C, Shi L, Wang F-S. Liver Injury in COVID-19: Management and Challenges. Lancet Gastroenterol Hepatol. 2020 May;5(5):428-30.

13. Feng G, Zheng KI, Yan Q-Q, et al. COVID-19 and Liver dysfunction: current insights and emergent therapeutic strategies. J Clin Transl Hepatol. 2020; 8:18-24.

14. Hamming I, Timens W, Bulthuis M, Lely AT, Navis GJ, van Goor H. Tissue distribution of ACE2 protein, the functional receptor for SARS coronavirus. A first step in understanding SARS pathogenesis. J Pathol. 2004;203:631-7.

15. Chai X, Hu L, Zhang Y, et al. Specific ACE2 expression in cholangiocytes may cause liver damage after 2019-nCoV infection. Pre-print bioRxiv 2020.

16. Chu KH, Tsang WK, Tang CS, et al. Acute renal impairment in coronavirus-associated severe acute respiratory syndrome. Kidney Int. 2005;67:698-705.

17. Fan C, Li K, Ding Y, Lu WL, Wang J. ACE2 Expression in Kidney and Testis May Cause Kidney and Testis Damage After 2019-nCoV Infection. medRxiv; 2020. DOI: 10.1101/2020.02.12.20022418.

18. Ye M, Wysocki J, William J, Soler MJ, Cokic I, Batlle D. Glomerular localization and expression of angiotensin-converting enzyme 2 and angiotensin-converting enzyme: Implications for albuminuria in diabetes. J Am Soc Nephrol. 2006;17:3067-75.

19. Daniel Batlle MJ, Soler MA, Sparks S, Hiremath AM, South PA, Welling. Sundararaman Swaminathan.Acute Kidney Injury in COVID-19: Emerging Evidence of a Distinct Pathophysiology. JASN Jul. 2020;31(7):1380-3.

\section{Tables}




\begin{tabular}{|c|c|}
\hline Variables & Number of patients (\%) \\
\hline \multicolumn{2}{|l|}{ Age } \\
\hline Mean $\pm S D$ & $55.5 \pm 11.6$ \\
\hline $30-39$ years & $11(11 \%)$ \\
\hline $40-49$ years & $26(26 \%)$ \\
\hline $50-59$ years & $22(22 \%)$ \\
\hline $60-69$ years & $26(26 \%)$ \\
\hline $70-79$ years & $6(6 \%)$ \\
\hline $80-89$ years & $9(9 \%)$ \\
\hline \multicolumn{2}{|c|}{ Severity of classification } \\
\hline Asymptotic & $22(22 \%)$ \\
\hline Mild & $24(24 \%)$ \\
\hline Moderate & $27(27 \%)$ \\
\hline Severe & $27(27 \%)$ \\
\hline \multicolumn{2}{|l|}{ Sex } \\
\hline Male & $66(66 \%)$ \\
\hline Female & $34(34 \%)$ \\
\hline \multicolumn{2}{|c|}{ Smoking status } \\
\hline Smoker & $10(10 \%)$ \\
\hline Non-smoker & $90(90 \%)$ \\
\hline
\end{tabular}




\begin{tabular}{|lll|}
\hline \multicolumn{2}{|l|}{ Table 2: The Mean $\mathbf{l}$ SD of the liver and renal biomarker levels in Covid -19 patients } & \\
\hline Biomarkers & Covid-19 patients $(\mathbf{n = 1 0 0 )}$ & Comments \\
\hline ALT (U/L) & $65.22 \pm 50.91$ & Elevated \\
\hline AST(U/L) & $53.95 \pm 46.50$ & Elevated \\
\hline Direct bilirubin (umol/L) & $41.03 \pm 20.20$ & Elevated \\
\hline Bilirubin(umol/L) & $50.89 \pm 32.62$ & Elevated \\
\hline Albumin (g/L) & $29 \pm 9.35$ & Reduced \\
\hline Creatinine(umol/L) & $185.38 \pm 33.99$ & Elevated \\
\hline Urea(mmol/L) & $19.59 \pm 14.36$ & Elevated \\
\hline Uric acid(mmol/L) & $0.30 \pm 0.31$ & Normal \\
\hline BUN (mol/L) & $8.85 \pm 5.10$ & Elevated \\
\hline $\mathrm{Na}(\mathrm{mmol} / \mathrm{L})$ & $148.03 \pm 15.81$ & Elevated \\
\hline $\mathrm{K}(\mathrm{mmol} / \mathrm{L})$ & $1.25 \pm 0.92$ & Reduced \\
\hline $\mathrm{P}(\mathrm{mmol} / \mathrm{L})$ & $1.08 \pm 0.69$ & Normal \\
\hline $\mathrm{Ca}(\mathrm{mmol} / \mathrm{L})$ & $2.21 \pm 0.47$ & Normal \\
\hline $\mathrm{Cl}(\mathrm{mmol} / \mathrm{l})$ & $111.95 \pm 11.67$ & Elevated \\
\hline $\begin{array}{l}\mathrm{Data} \text { presents as Mean } \pm \text { SD for liver biomarkers levels such as ALT (alanine aminotransferase), } \\
\text { acid, BUN, and electrolytes. The levels of markers were compared with normal reference range. }\end{array}$ \\
\hline
\end{tabular}


Table 3 Comparison between infected and non-infected patients on the basis of levels of liver and renal biomarkers

\begin{tabular}{|c|c|c|c|}
\hline Parameters & Covid-19 patients $(n=100)$ & Control $(n=90)$ & P-Value \\
\hline $\operatorname{ALT}(\mathrm{U} / \mathrm{L})$ & $65.22 \pm 50.91$ & $12.8 \pm 8.6$ & $0.001^{* *}$ \\
\hline $\mathrm{AST}(\mathrm{U} / \mathrm{L})$ & $53.95 \pm 46.50$ & $15.7 \pm 7.3$ & $0.002^{* *}$ \\
\hline Direct bilirubin (umol/L) & $41.03 \pm 20.20$ & $1.5 \pm 0.1$ & $<0.001^{* \star}$ \\
\hline Bilirubin(umol/L) & $50.89 \pm 32.62$ & $3.4 \pm 1.5$ & $<0.001^{* \star}$ \\
\hline Albumin $(\mathrm{g} / \mathrm{L})$ & $29 \pm 9.35$ & $40.7 \pm 31.9$ & $0.02^{*}$ \\
\hline Creatinine (umol/L) & $185.38 \pm 33.99$ & $78.45 \pm 50.99$ & $<0.001^{\star \star}$ \\
\hline Urea(mmol/L) & $19.59 \pm 14.36$ & $3.27 \pm 1.30$ & $0.002^{\star *}$ \\
\hline Uric acid(mmol/L) & $0.30 \pm 0.31$ & $0.27 \pm 0.12$ & $>0.05$ \\
\hline BUN (mol/L) & $8.85 \pm 5.10$ & $3.60 \pm 1.99$ & $>0.05$ \\
\hline $\mathrm{Na}(\mathrm{mmol} / \mathrm{L})$ & $148.03 \pm 15.81$ & $138.17 \pm 78.99$ & $0.04 *$ \\
\hline $\mathrm{K}(\mathrm{mmol} / \mathrm{L})$ & $1.25 \pm 0.92$ & $3.99 \pm 2.92$ & $0.03^{*}$ \\
\hline $\mathrm{P}(\mathrm{mmol} / \mathrm{L})$ & $1.08 \pm 0.69$ & $0.84 \pm 0.30$ & $>0.05$ \\
\hline $\mathrm{Ca}(\mathrm{mmol} / \mathrm{L})$ & $2.21 \pm 0.47$ & $2.30 \pm 1.99$ & $>0.05$ \\
\hline $\mathrm{Cl}(\mathrm{mmol} / \mathrm{L})$ & $111.95 \pm 11.67$ & $105.30 \pm 9.99$ & $0.02^{*}$ \\
\hline
\end{tabular}

Table 4: Comparison of levels of liver biomarkers between male and female Covid-19 patients.

\begin{tabular}{llll} 
Parameters & Female $(\mathrm{n}=\mathbf{3 4})$ & Male $(\mathrm{n}=\mathbf{6 6})$ & $\boldsymbol{P}$-Value \\
\hline ALT & $22.38 \pm 11.07$ & $30.8 \pm 12.6$ & $\mathbf{0 . 0 5 ^ { * }}$ \\
\hline AST & $20.3 \pm 11.27$ & $55.7 \pm 13.98$ & $\mathbf{0 . 0 4 *}$ \\
\hline Direct bilirubin & $38.33 \pm 15.83$ & $60 \pm 49.1$ & $\mathbf{0 . 0 1 *}$ \\
\hline Bilirubin & $15.64 \pm 7.80$ & $87.1 \pm 22.5$ & $\mathbf{0 . 0 3 *}$ \\
\hline Albumin & $9.4 \pm 9.11$ & $8.7 \pm 5.9$ & $>0.05$
\end{tabular}

Data was analyzed by T-test to compare between two genders patients with Covid-19 and a statistical significance differences was considered as $\mathrm{P}<0.05^{\star}$ 


\begin{tabular}{|llll|}
\hline \multicolumn{3}{|l|}{ Table 5: Comparison of renal biomarkers between male and female Covid-19 patients } & \\
\hline Parameters & Female $(\mathbf{n}=\mathbf{3 4})$ & Male $(\mathbf{n}=66)$ & P-Value \\
\hline Creatinine(umol/L) & $172.95 \pm 17.63$ & $102.67 \pm 20.98$ & $\mathbf{0 . 0 4 *}$ \\
\hline Urea $(\mathrm{mmol} / \mathrm{L})$ & $17.53 \pm 12.58$ & $10.11 \pm 6.16$ & $>0.05$ \\
\hline Uric acid(mmol/L) & $0.50 \pm 0.37$ & $5.95 \pm 4.63$ & $\mathbf{0 . 0 1 *}$ \\
\hline $\mathrm{BUN}(\mathrm{mol} / \mathrm{L})$ & $6.36 \pm 5.29$ & $68.05 \pm 8.63$ & $\mathbf{0 . 0 2 *}$ \\
\hline $\mathrm{Na}(\mathrm{mmol} / \mathrm{L})$ & $140.35 \pm 13.99$ & $144.77 \pm 8.77$ & $>0.05$ \\
\hline $\mathrm{K}(\mathrm{mmol} / \mathrm{L})$ & $3.83 \pm 1.1$ & $1.77 \pm 0.77$ & $\mathbf{0 . 0 5 *}$ \\
\hline $\mathrm{P}(\mathrm{mmol} / \mathrm{L})$ & $1.17 \pm 0.92$ & $0.50 \pm 0.46$ & $>0.05$ \\
\hline $\mathrm{Ca}(\mathrm{mmol} / \mathrm{L})$ & $2.12 \pm 0.57$ & $1.00 \pm 0.22$ & $>0.05$ \\
\hline $\mathrm{Cl}(\mathrm{mmol} / \mathrm{L})$ & $112.13 \pm 10.57$ & $108.12 \pm 11.57$ & $\mathbf{0 . 0 4 *}$ \\
\hline $\begin{array}{l}\text { Data was analyzed by } \mathrm{T} \text {-test to compare between two genders patients with Covid-19 and a statistical } \\
\text { significance differences was considered as } \mathrm{P}<0.05^{*}\end{array}$ & \\
\hline
\end{tabular}


Table 6: A one-way between subject's ANOVA was conducted to compare severe cases with asymptotic and mild cases in the levels of renal and liver markers.

\begin{tabular}{|c|c|c|c|c|c|c|}
\hline \multirow[t]{2}{*}{ Biomarkers } & \multicolumn{3}{|c|}{$\begin{array}{l}\text { Asymptotic cases }(n=22) \text { Vs. Severe } \\
\text { cases }(n=27)\end{array}$} & \multicolumn{3}{|c|}{$\begin{array}{l}\text { Mild to Moderate cases }(n=51) \text { Vs. Severe } \\
\text { cases }(n=27)\end{array}$} \\
\hline & $\begin{array}{l}\text { Mean } \\
\text { Diff. }\end{array}$ & $\begin{array}{l}95.00 \% \mathrm{Cl} \text { of } \\
\text { diff. }\end{array}$ & $P$ & $\begin{array}{l}\text { Mean } \\
\text { Diff. }\end{array}$ & $\begin{array}{l}95.00 \% \mathrm{Cl} \text { of } \\
\text { diff. }\end{array}$ & $P$ \\
\hline $\operatorname{ALT}(\mathrm{U} / \mathrm{L})$ & 88.93 & 65.20 to 112.7 & $<0.001^{\star *}$ & 81.83 & 62.17 to 101.5 & $<0.001^{\star *}$ \\
\hline $\mathrm{AST}(\mathrm{U} / \mathrm{L})$ & 47.36 & 18.34 to 76.38 & $0.0005^{\star *}$ & 43.21 & 19.16 to 67.26 & $0.001 * *$ \\
\hline $\begin{array}{l}\text { Direct bilirubin } \\
\text { (umol/L) }\end{array}$ & 15.4 & -12.36 to 43.16 & 0.3874 & -5.433 & -28.44 to 17.57 & 0.8405 \\
\hline Bilirubin(umol/L) & 23.06 & 22.58 to 46.70 & $0.022^{*}$ & -9.587 & -38.29 to 19.11 & 0.707 \\
\hline Albumin $(\mathrm{g} / \mathrm{L})$ & 17.36 & 2.34 to 20.68 & $0.021 *$ & 18.21 & 1.16 to 20.26 & $0.023^{*}$ \\
\hline Creatinin(umol/L) & 30.62 & 16.2 to 44.2 & $<0.001^{\star *}$ & 24.1 & 12.6 to 35.7 & $<0.001$ ** \\
\hline Urea(mmol/L) & 11.42 & 1.909 to 20.92 & $0.014^{*}$ & 6.977 & -0.9008 to 14.85 & 0.093 \\
\hline BUN (mol/L) & 1.629 & -2.163 to 5.420 & 0.5646 & -0.07495 & -3.217 to 3.067 & 0.998 \\
\hline $\mathrm{Na}(\mathrm{mmol} / \mathrm{L})$ & 36.589 & $\begin{array}{l}12.084 \text { to } \\
35.26\end{array}$ & $0.017 *$ & 26.388 & 5.7997 to 28.58 & $0.012^{*}$ \\
\hline $\mathrm{K}(\mathrm{mmol} / \mathrm{L})$ & 0.5402 & $\begin{array}{l}-0.08487 \text { to } \\
1.165\end{array}$ & 0.1043 & 0.2274 & $\begin{array}{l}-0.2906 \text { to } \\
0.7454\end{array}$ & 0.5504 \\
\hline $\mathrm{Cl}(\mathrm{mmol} / \mathrm{l})$ & 32.79 & 3.118 to 9.711 & $0.042^{*}$ & 20.179 & 1.722 to 8.080 & $0.0027^{* *}$ \\
\hline
\end{tabular}


Table 7: Multiple logistic regression analysis for patients had Covid-19 infection and its association with liver and renal biomarkers.

\begin{tabular}{|c|c|c|c|}
\hline Variables & OR & $95.00 \% \mathrm{Cl}$ & $P$ \\
\hline Age (years) & 0.9772 & 0.9345 to 1.020 & $>0.001$ \\
\hline \multicolumn{4}{|l|}{ Gender } \\
\hline Male & 1.0 & Reference & \multirow[t]{2}{*}{$0.03^{\star}$} \\
\hline Female & 2.187 & 1.102 to 4.876 & \\
\hline $\operatorname{ALT}(U / L)$ & 7.01 & 0.9975 to 6.023 & $<0.001 * \star$ \\
\hline $\operatorname{AST}(U / L)$ & 0.9816 & 0.9495 to 1.002 & $>0.001$ \\
\hline Direct bilirubin (umol/L) & 1.001 & 0.9824 to 1.021 & $>0.001$ \\
\hline Bilirubin(umol/L) & 6.9943 & 1.9745 to 6.010 & $0.003^{*}$ \\
\hline Creatinin(umol/L) & 5.999 & 1.9934 to 5.004 & $0.002^{\star}$ \\
\hline Urea(mmol/L) & 0.9736 & 0.9270 to 1.019 & $>0.001$ \\
\hline BUN (mol/L) & 0.8938 & 0.7949 to 0.9883 & $>0.001$ \\
\hline $\mathrm{Na}(\mathrm{mmol} / \mathrm{L})$ & 7.039 & 2.9871 to 7.099 & $<0.001 * \star$ \\
\hline $\mathrm{K}(\mathrm{mmol} / \mathrm{L})$ & 1.608 & 0.6311 to 4.278 & $>0.001$ \\
\hline $\mathrm{Cl}(\mathrm{mmol} / \mathrm{l})$ & 3.009 & 0.9976 to 2.022 & $0.004 *$ \\
\hline \multicolumn{4}{|c|}{ Category of Covid-19 patients } \\
\hline Asymptotic cases, $n=22$ & 1.0 & Reference & \\
\hline
\end{tabular}

